\title{
Espaço, Economia e História Regional no Brasil
}

\section{Walter Luiz Carneiro de Mattos Pereira}

\section{(2) OpenEdition \\ Journals}

\section{Edição electrónica}

URL: http://journals.openedition.org/espacoeconomia/2275

DOI: 10.4000/espacoeconomia.2275

ISSN: 2317-7837

\section{Editora}

Núcleo de Pesquisa Espaço \& Economia

\section{Refêrencia eletrónica}

Walter Luiz Carneiro de Mattos Pereira, «Espaço, Economia e História Regional no Brasil », Espaço e Economia [Online], 8| 2016, posto online no dia 03 outubro 2016, consultado o 23 setembro 2020. URL : http://journals.openedition.org/espacoeconomia/2275; DOI : https://doi.org/10.4000/ espacoeconomia.2275

Este documento foi criado de forma automática no dia 23 setembro 2020.

(C) NUPEE 


\title{
Espaço, Economia e História Regional no Brasil
}

\author{
Walter Luiz Carneiro de Mattos Pereira
}

\section{REFERÊNCIA}

MASSA, Françoise. Um francês no Vale do Carangola: Alexandre Bréthel, farmacêutico e fazendeiro (pesquisa sobre sua correspondência brasileira, 1862 - 1901). Belo Horizonte, Crisálida, 2016. Tradução de Heloisa Azevedo da Costa. 504 p.

1 Eis um livro essencial como fonte para escrever a história, ainda tão tímida, do Noroeste Fluminense. Na verdade, não se pode falar de uma história recortada dentro dos limites políticos da província fluminense no século XIX, mas de uma região muito mais ampla de um "Vale do Paraíba estendido"1, que prossegue não só pelo Rio de Janeiro, mas atinge outras plagas das províncias de Minas Gerais e do Espírito Santo. Digo isso porque não se pode pensar a economia do norte fluminense no século XIX sem integrá-la ao sul da província capixaba e à Zona da Mata mineira. A própria dimensão espacial recortada no livro de Francoise Massa mostra essa simbiose, pois perpassa as linhas fronteiriças do mapa político e aponta para a confluência entre interesses e negócios nesta tríplice fronteira do sudeste cafeeiro. Falo em cafeeiro pelo fato de que toda essa região, incluindo o município de Campos dos Goytacazes, cujos limites tocavam o extremo norte da Província do Rio de Janeiro, constituía-se em uma das áreas mais dinâmicas da expansão do café fluminense a partir de 1870.

O livro de Massa (existe uma edição de 1977, em francês) é fruto de tese de doutorado defendida na Sorbonne em 1975 e explora a correspondência enviada por AlexandreMarie Bréthel à sua família e a outras pessoas de seu círculo na Bretanha, França, entre os anos de 1862 e 1900 - incluindo 68 cartas escritas de Santo Antônio do Carangola, atual Porciúncula, no Rio de Janeiro, dentre os mais de mil documentos (cartas, fotos, páginas de livro de contas, poemas e receitas) identificados por Françoise Massa no acervo da família e em outros arquivos. Fora isso, Massa recorre a uma série de 
instituições no Brasil e na França para alimentar sua pesquisa, desenhada em quatro partes: uma trata da vida de Bréthel na França antes de sua vinda para o Brasil e de emigrantes franceses no país; a segunda parte visa explicar o que é o Vale do Rio Carangola na segunda metade do século XIX, a família e seus negócios e suas correspondências; a terceira diz respeito à sua fazenda, à vida cotidiana e às atividades agrícolas na década de 1870; a quarta e última reflete sobre a Estrada de Ferro do Carangola e a abolição da escravidão na década de 1880. Por fim, logo depois da conclusão, Massa constrói um apêndice com 69 cartas, além da reprodução de 35 documentos diversos, todos traduzidos para o português. 0 livro contempla imagens e mapas da região e uma bibliografia extensa que, se não a associa a uma linha específica da historiográfica francesa - pois trata-se de tese na área de letras -, indica um momento referente à terceira fase dos Annales, em especial no que concerne aos estudos sobre história cultural. 0 trabalho de Massa, como sugere Heloisa de Azevedo da Costa (tradutora e apresentadora do livro), guarda um viés antropológico ao seguir as cartas de Bréthel.

3 Sem dúvida, estamos defronte a uma obra que vislumbra a conexão entre espaço e economia no século XIX. Assim, no que tange à seleção dos temas abordados nas correspondências, gostaria de destacar aqueles que, para mim, são muito instigantes no processo de construção da história econômica sobre a região envolvendo Campos dos Goytacazes, Zona da Mata mineira e sul do Espírito Santo: expansão da fronteira agrícola, café, características físicas, transporte, agricultura, extinção das matas, vida de fazendeiro, economia local, convivência com famílias indígenas, situação dos escravos africanos, violência, surgimento das vilas, abolição da escravatura, chegada da estrada de ferro, imigração francesa e ocupação territorial.

o Vale do Carangola acompanha o curso do rio que parte da Zona da Mata de Minas Gerais, ou seja, do sudeste/leste de Minas, e adentra pelo extremo noroeste fluminense até encontrar o rio Muriaé, em Itaperuna, e daí seguir seu curso com esse nome até desaguar no rio Paraíba próximo à cidade de Campos dos Goytacazes. $O$ rio Carangola é um subafluente do rio Paraíba do Sul. A propriedade de Bréthel, denominada Fazenda São Joaquim, localizada em Santo Antônio do Carangola, era parte desse Vale, uma das regiões mais prósperas e promissoras da expansão cafeeira fluminense no final do século XIX. Santo Antônio do Carnagola era uma pequena vila situada nos limites do município de Campos dos Goytacazes que, na década de 1850, encontrava-se sob jurisdição da Freguesia de Nossa Senhora de Natividade do Carangola. Talvez ali, no acervo paroquial, Massa pudesse localizar os registros paroquiais da família Bréthel, considerando a organização da administração eclesiástica no Brasil Império que dava a Igreja a responsabilidade do registro de nascimento, casamento e obito de livres e escravos.

5 Campos dos Goytacazes nas décadas de 1870 e 1870, segundo dados do censo do Império e relatórios de presidentes de província, tinha uma população expressiva, algo próximo a 90 mil habitantes entre livres e escravos. A população cativa girava em torno de 25 mil escravos nos anos próximos à abolição da escravidão. As cartas de Bréthel registram a produção cafeeira ascendente na região, ainda que enfrentasse problemas relativos à mão-de-obra e à oscilação dos preços do produto no mercado, notadamente na década de 1880. Bréthel reclama em seus escritos da dificuldade de contratar mão-de-obra para expandir sua colheita. O sucesso do café estava necessariamente ligado à disponibilidade de trabalhadores. Diz, por exemplo, que de um grupo de 30 pessoas que 
trabalham em suas terras, apenas oito são escravos. Diante desta exposição, Bréthel revela-se antiescravista, pois sequer havia comprado escravos para tocar sua lavoura e os cativos que mantinha teriam sido, todos eles, recebidos como dote de seu casamento com Guilhermina Leopoldina Lannes Dantas Brandão - filha de Joaquim de Lannes Dantas Brandão e Francisco Leopoldina Martins de Oliveira Leme, membros de duas famílias pioneiras na ocupação da região.

6 Sua informação é preciosa e relevante, pois estabelece certa quantificação da força de trabalho utilizada nos cafezais locais, ainda que as freguesias do noroeste fluminense vinculadas a Campos dos Goytacazes como Nossa Senhora de Natividade do Carangola e Nossa Senhora da Piedade de Laje do Muriaé, nos limites com Minas Gerais, e a freguesia de Senhor Bom Jesus do Itabapoana, nos limites com o Espírito Santo, fossem as únicas que apresentassem aumento da população escrava nas décadas próximas à abolição da escravidão - em função da rápida expansão cafeeira pela região. Entretanto, esse perfil demográfico não correspondia à contínua e crescente demanda de braços para os cafezais, como nos mostra a composição da força de trabalho nas terras de Bréthel.

7 Portanto, a correspondência de Bréthel e as observações de Massa confirmam as informações de caráter demográfico sobre a região, mostrando que, além da população escrava, aumentava também o contingente de homens livres, com destaque para as famílias de colonos - embora sua manutenção fosse considerada dispendiosa pelo fazendeiro francês. Dessa forma, o número de trabalhadores livres na lavoura de Bréthel superava em quatro vezes o número de escravos. Outro aspecto relacionado ao trabalho no cafezal do noroeste fluminense comentado por ele com certa ênfase e decepção recai sobre a situação das populações indígenas, estas já nos seus estertores: os índios que ali viviam estavam sujeitos a uma violência brutal e em total estado de degradação social, precisamente as famílias puris que habitavam aquela região antes do choque com a expansão da fronteira cafeeira. Desde a primeira metade do século XIX, no entorno do extremo norte da província fluminense, os registros paroquiais da Freguesia de Santo Antônio de Guarulhos, do lado norte do Rio Paraíba, indicam diversos casamentos com mulheres índias que carregavam a identificação puri no sobrenome. Aliás, um dos tópicos enfatizados por Bréthel versa sobre o fato de que a violência era regra - não só em relação aos índios, mas, também, em decorrência da escravidão, com assassinatos de senhores, escravos, colonos e fazendeiros. Neste aspecto, suas cartas testemunham importantes peculiaridades acerca das regiões de fronteira aberta.

Outro assunto destacado pelo francês era o acelerado processo de destruição das matas: neste caso, o lucrativo comércio de madeiras, especialmente o jacarandá, uma das principais mercadorias comercializadas e transportadas primeiro pelos rios e, depois, pelas ferrovias que cruzavam Campos dos Goytacazes.

9 Por outro lado, uma das chaves que nos permite ratificar o dinamismo econômico da região desde a introdução do café foi a construção da Estrada de Ferro do Carangola a partir de 1875 e sua chegada ao extremo norte fluminense na década de 1880. Campos dos Goyatacazes, ao expressar sua magnitude econômica no final do século XIX, ocupa um espaço da economia mercantil escravista brasileira de clara nuance capitalista, ou seja, apresentando-se como um espaço da economia de mercado cujo território era recortado por quase quatrocentos quilômetros de ferrovias já na década de 1880: a Estrada de Ferro São Sebastião, que ligava a cidade aos principais campos da produção 
açucareira local; a Estrada de Ferro Campos Macaé, que vinculava a cidade ao porto de Imbetiba, em Macaé, principal escoadouro de café e do açúcar; e a Estrada de Ferro do Carangola, que unia a cidade ao extremo norte cafeeiro da província fluminense, apontando para os limites de Minas Gerais e Espírito Santo. Ao ser finalizada, esta ferrovia alcançava cento e oitenta e oito quilômetros e transportava mais de doze mil toneladas de café que, transbordados para a Estrada de Ferro Campos Macaé, chegavam ao porto da cidade de Macaé com o dobro dessa tonelagem. Não por acaso, Bréthel deixa claro o papel que as ferrovias cumprem naquela conjuntura e não deixa escapar que o processo de montagem das mesmas demandou querelas e lutas permanentes, em especial entre proprietários locais, pela possibilidade da ferrovia tocar em suas terras algo não atraía o próprio Bréthel, cujos trilhos tangiam suas terras por dois vértices. Por um lado, a Estrada de Ferro do Carangola, por outro, a Estrada de Ferro Leopoldina, que por terras mineniras atingia o Vale do Rio Doce. Bréthel desejava usufruir da modernidade, mas, ao mesmo tempo, incomodava-se com sua proximidade. No entanto, estamos diante de um defensor da idéia de progresso e de um leitor assíduo e simpatizante das obras de Augusto Comte, tendo encomendado de Paris e recebido em sua fazenda a obra A Filosofia Positiva.

10 Tais ferrovias foram montadas com capitais locais e juros garantidos pela província fluminense, em que sócios constituintes como Cardoso Moreira, Saturnino Braga e Francisco Portella buscavam negociantes e fazendeiros da região para investirem no negócio, evidenciando assim a disponibilidade de capitais (Bréthel cita Portella em uma de suas cartas relatando a visita deste em sua fazenda). Numa viagem que começa na estação de Porto Alegre (atual Itaperuna), ao dispor do trem para levar sua família para conhecer a cidade e o mar em Campos dos Goytacazes em 1886, Bréthel revela-nos o vigor da economia regional. Mais uma vez, suas observações sobre Campos evidenciavam o dinamismo local, contrastando com a o cenário de crise do escravismo e do café na província (em especial no Vale do Paraíba tradicional) agravada pelo dispositivo legal que começaria a por abaixo a escravidão a partir de 1850: a Lei do Fim do Tráfico, seguida da Lei da Ventre Livre, em 1871, da Lei do Sexagenário, em 1884 ; e por fim da Lei da Abolição, de 1888.

11 Reforçando tal dinamismo, vale dizer que Campos dos Goytacazes possuía dois bancos na segunda metade do século XIX: o Banco de Campos e o Banco Comercial e Hipotecário de Campos, que operavam em magnitude, sem esquecer-se de uma Caixa Econômica com robustos valores aplicados em títulos da dívida pública. Os empréstimos efetuados por tais instituições, em valores expressivos, representavam baixo risco, indicando forte ação financeira nos negócios agrícola e mercantil, ainda que o crédito se constituísse, em quase sua totalidade, de letras descontadas em curto prazo. Bréthel dá a senha para a conjuntura positiva ao mencionar a pujante economia da cidade, tida por ele como rica, em que os dois bancos locais não mais aceitavam depósitos remunerados a juros, pois não teria onde empregá-los. A carta enviada aos parentes franceses demonstra surpresa e espanto pontuados por uma prolongada exclamação.

12 Enfim, Françoise Massa consegue expor através das cartas de Brethel um rico e precioso trabalho de garimpagem que opera uma densidade de informações para o ofício do historiador. Suas observações e escolhas são fundamentais para se pensar o papel da região na conjuntura econômica e social do Império. Ao elaborar essa resenha, minhas escolhas buscaram pinçar elementos que ajudem a pensar sobre a história econômica 
da região, no século XIX, a partir da projeção do espaço na economia e da economia no espaço.

\section{BIBLIOGRAFIA}

ALVARENGA, João de. Almanak Marcantil, Industrial, Administrativo e Agrícola da Cidade e do Município de Campos para 1881. Campos, Typographia do Monitor Campista, 1882.

Almanak Mercantil, Industrial, Administrativo e Agrícola da Cidade e Município de Campos para o ano de 1885. Campos, Typographia do Monitor Campista, 1886.

DONALD JR., Cleveland. Slavery and Abolition in Campos. Tese (Doutorado em Filosofia), Cornell University, Estados Unidos, 1973.

FARIA, Sheila de Castro. Terra e trabalho em Campos dos Goytacazes (1850 - 1920). Dissertação de Mestrado, Programa de Pós-graduação em História Social, da Universidade Federal Fluminense, Niterói, Rio de Janeiro, 1986.

MUAZE, Mariana e SALLES, Ricardo (orgs.). O Vale do Paraíba e o Império do Brasil nos quadros da Segunda Escravidão. Rio de Janeiro : 7 Letras, 2015.

MELLO, José Alexandre Teixeira de. Campos dos Goytacazes em 1881. Rio de Janeiro, Typographya Laemmert e Cia, 1886.

PEREIRA, Walter Luiz Carneiro de Mattos. Crédito e Bancos em Campos dos Goytacazes (1863 1888). In: CORTE, Andrea Telo da (org.). Novos Capítulos da História Fluminense. Rio de Janeiro: FUNARJ/Imprensa Oficial, 2014.

. Francisco Ferreira Saturnino Braga: negócios e fortuna em Campos dos Goytacazes (século XIX). Revista História (São Paulo), vol. 13, no 2, 2012.

. Circuito de Integração Regional: a Estrada de Ferro Campos - Carangola no século XIX; in: RIBEIRO, Gladys Sabina; MARTINS, Ismênia de Lima; e FERREIRA, Tânia Maria Bessone da Cruz (orgs.) Os oitocentos sob novas perspectivas. São Paulo, Alameda, 2014.

\section{NOTAS}

1. O termo remete às discussões efetuadas no Grupo do Vale, ou mais precisamente, grupo de pesquisa que vem desenvolvendo debates e trabalhos sobre o Vale do Paraíba e a Segunda Escravidão sob coordenação de Ricardo Salles (UniRio), Rafael Marquese (USP) e Mariana Muaze (UniRio). Neste aspecto, a leitura da fonte bibliográfica incorpora-se às pesquisas que realizo sobre o norte fluminense, no século XIX. 


\section{AUTOR}

\section{WALTER LUIZ CARNEIRO DE MATTOS PEREIRA}

LAPEDHE - Laboratório de Pesquisa e Documentação em História Econômica e Social. Professor Adjunto IV do Departamento de História da Universidade Federal Fluminense, Campos dos Goytacazes 